\title{
Is it helpful to send copies of clinic letters to women following consultations in sexual health?
}

\author{
Anna Glasier, Ailsa Gebbie, Fiona Cowan
}

\section{Background}

The proposal to send a patient the copy of the letter which is sent to the general practitioner (GP) following a National Health Service (NHS) consultation has been discussed with varying degrees of support and has also been raised within the Faculty of Family Planning and Reproductive Health Care. ${ }^{1}$ The England and Wales NHS Plan states that in future "letters between clinicians about an individual patient's care will be copied to the patient as a matter of right". 2 The Working Group set up by the Department of Health (DH) to discuss implementation of the policy concluded that it was important for improving communication between patients and professionals in the NHS. ${ }^{3}$

As a preliminary measure, we decided to attempt to assess the acceptability of such a procedure both to the women who receive the copy letters and to the staff who write and type them.

For a few months during 2003, three consultant gynaecologists within our service agreed to send a copy letter to women following a new patient consultation in a specialist medical gynaecology clinic. The woman was asked at the end of the consultation if she would like to receive a copy of the letter, and when the copy letter was sent a short questionnaire assessing the acceptability of the process was enclosed and the patient asked to return it in a stamped addressed envelope. A total of 54 women returned a completed questionnaire.

\section{Comments from women}

All but one woman found their letter very easy to understand; one found it quite easy, but no one found it difficult to understand their letter. Two women said that their letter contained technical jargon (the words 'amenorrhoea' and 'adnexa') that they did not understand. Three women reported that there were minor inaccuracies in the letter relating mainly to dates of past events. Two women said that they were surprised by something written in the letter.

All but two women said that they found it useful to have a copy of the letter to the GP. One woman commented "it's just more paper clutter for me" and added that she was concerned about the cost to the NHS if this practice became the norm. In total, all but two women wanted to receive copy letters in the future.

Several women added comments to the back of the questionnaire, which are detailed below.

"I think having a copy gives one a real sense of being involved in the process, rather than feeling an object of the process. Some people might prefer to be excluded. It might be an idea to allow patients to register in or out."

J Fam Plann Reprod Health Care 2005; 31(2): 101-102

Family Planning and Well Woman Services, Edinburgh, UK Anna Glasier, MD, FRCOG, Consultant and Director Ailsa Gebbie, FRCOG, MFFP, Consultant Gynaecologist Fiona Cowan, Business Manager

Correspondence to: Dr Ailsa Gebbie, Family Planning and Well Woman Services, 18 Dean Terrace, Edinburgh EH4 1NL, UK Tel: +44 (0) 131332 0390. E-mail: ailsa.gebbie@|pct.scot.nhs.uk
"I now have all the information I need to help myself and also not waste the medical profession's time concerning this matter."

"I think this is excellent - very helpful. It's a good reminder and keeps it all transparent and confirms my trust in those involved. It's important that it stays as a letter between doctors, rather than having two different audiences, I think, in sustaining accurate professional communication."

“Ideal to have a record as I am not a good 'historian' and forget what happens."

"Congratulations, I think this is an extremely good idea. It will certainly help to minimise the misunderstandings which can sometimes follow clinic visits when patients don't remember what was said because they are perhaps embarrassed or upset at the time."

"The doctor explained everything very clearly to me during my visit to the clinic but it is good to have this in writing as you do forget very quickly after the examination."

There was, however, one unfortunate incident. One woman received a letter intended for another patient. She phoned to inform us of this and received an apology and a copy of the correct letter. She returned her questionnaire and wrote:

"I was not very impressed at receiving another patient's letter and this caused much upset and worry. I can only assume that the other lady received my letter [actually she did not] and I felt that the tone of this letter in parts talked down about me and feel in areas it could have been worded a little better ... [this woman, however, went on to add] ...but, all in all, I feel receiving a copy of letters to my GP is helpful and would like to receive them in the future".

This was the only woman who wrote anything critical about the content or style of the letter.

\section{Comments from administrative staff}

"I had generally negative views about the process. The secretaries involved with the specialist clinics are particularly busy and struggle with the workload. The procedure is slightly complicated and therefore open to mistakes. To be selective about which patients to send letters to, and at a time when the NHS is struggling financially, it seems an unnecessary expense" [stamps, stationery, time, etc.].

"It seemed like a lot more work, even although the letter was already typed to the GP, just adding on the PS to the patient [asking her to contact the clinic and not the GP if she had any questions about the letter] and typing out another envelope and enclosing the form to be returned in the prepaid envelope and ensuring that the correct letter went to the correct patient was very time consuming."

\section{Comments from medical staff}

"I was aware, when writing the letter to the GP, of slightly changing the style in which I phrased some of the discussion. I also felt myself being more careful how I worded the reporting of potentially sensitive findings such as obesity or hirsutism. It was particularly difficult in cases where I felt that there was nothing very much wrong with 
the patient other than her inability to cope very well with life in general and a couple of times I did not send the letter."

"One woman told me how helpful my letter had been and put in writing the problem she was experiencing of which her GP had been dismissive. My general feeling is that copies of clinic letters are very helpful for patients attending clinics with ongoing chronic diseases but are of less value in the sexual health setting where we generally are good at offering explanations and choices to women anyway. I have major worries about letters with very personal information relating to sexual health and relationships going astray in the post."

"I do not look forward to having to copy all clinic letters to patients because of the added time and effort it will take. Nor do I look forward to having to make time to speak to patients over the phone to explain my letters. I would rather spend the time having a good consultation and communicating well at the time."

\section{Discussion}

It is difficult to draw precise conclusions from this small project as not all the participating women wished to receive a copy letter and the medical staff did not always offer women the opportunity to receive a copy. However, based on the questionnaires returned, it would seem that many women highly value getting a copy of the letter that is sent to their GP. By providing the patient with an accurate account of what was discussed at the consultation, it is possible that this policy might reduce complaints or even litigation.

No one found the letters difficult to understand, and even when technical jargon was used it did not seem to be problematic. The inaccuracies that did occur in the letters were of a minor nature and the surprises were informative other than upsetting.

The one major incident related to a woman being sent a copy of the wrong letter. The DH Working Group points out "experience shows that risks to confidentiality infrequently materialise in practice. They are the same risks attached to handling of all confidential personal data ... however, inevitably there will be errors and confidentiality will be breached".3

Doctors have concerns about distressing or upsetting patients by what they communicate in the letters and the extent of this will clearly vary in different specialties. This may lead to important or relevant information being deliberately omitted as has been shown in psychiatric outpatient letters. ${ }^{4}$ Training and reassurance about copying letters to patients may be required before large-scale implementation of this scheme.

The cost of sending copy letters to individual patients is not inconsiderable. An estimation of the cost implications for routinely sending a second-class letter following all NHS consultations in England is $£ 8.17$ million for stamps alone. Including manpower costs estimated at $£ 6$ per hour would increase the costs of the scheme to over $£ 13$ million. 5 This is equivalent to the running costs of 13 fully staffed hospital wards for 1 year. It will be important to respect the patient's right to choose whether or not they receive a copy of the letter, and the patient may have to be willing to provide a stamped addressed envelope in order to make the scheme financially viable.

Statements on funding and competing interests

Funding. None identified.

Competing interests. None identified.

References

1 Faculty News. London, UK: Faculty of Family Planning and Reproductive Health Care, July 2004

2 Department of Health. The NHS Plan. London, UK: Stationery Office, 2000.

3 Working Group on Copying Letters to Patients. Copying Letters to Patients: A Report to the Department of Health and Draft Good Practice Guidelines for Consultation. Leeds, UK: Department of Health, 2002.

4 Murray GK, Nandhra H, Hymas N, Hunt N. Psychiatrists omit information from letters when they know patients will be sent copies. BMJ 2003; 326: 449.

5 Housden PL. Do patients want copies of their letters? bmj.com Rapid Responses 2004; 328: 733

\section{Book Reviews}

Demonstrating Your Competence 1: Healthcare Teaching. R Chambers, K Mohanna, G Wakley and D Wall. Oxford, UK: Radcliffe Medical Press Ltd, 2004. ISBN: 185775607 X. Price: $£ 21.95$. Pages: 224 (paperback)

Appraisal and revalidation are topics that even the most resistant of doctors can no longer ignore. This book seeks to provide a structure for teachers in the various health-related professions to be used to undertake and document their competence in their various educational activities. The chapters are constructively divided into recognised educational areas, each beginning with a short review of the topic. The authors choose to use the construct of 'the evidence cycle' as the basis for producing documentation and then set out to demonstrate how the process can be undertaken by using everyday examples. The example exercises are commonly encountered and practical - the authors wisely emphasise the importance of choosing a simple task for an evidence cycle.

The format of the chapters is somewhat repetitive but this is balanced against the reality that the five stages of the cycle of evidence are firmly embedded into long-term memory by the end of the book. Teachers with little formal knowledge or experience of education and teaching should find the text constructive and practical. Those with more experience will find the book provides a useful summary. The book does provoke thought, and in the case of the reviewer motivated her to undertake an evidence cycle related to appraisals. This rather suggests that the text achieved its goal.

Reviewed by Dr Elizabeth S Nyholm, FRCGP, MFFP GP Tutor, Castle Vale Health Centre, Birmingham, UK

Demonstrating your Competence 2. Women's Health. R Chambers, G Wakley and J Jenkins. Oxford, UK: Radcliffe Medical Press, 2004. ISBN: 185775843 9. Price: £21.95. Pages: 248 (paperback)

This book sets out to help GPs with their personal development plans and the collection of information necessary for appraisal and revalidation. It provides numerous examples of subjects that could be studied, and sets out a template for the collection of evidence. This template could also be used by doctors in any specialty to produce a portfolio of their learning. The first three chapters give a detailed account of personal development plans and how to demonstrate competence. This is useful as a reference but contains so much information it is easy to become overwhelmed.

Chapter 3 has an easily followed procedure for setting up a research project in general practice. However, the process involves a large input of time and the conclusion reached in the example, namely "you revise your plans as the scale of the work required is becoming out of all proportion" is a useful warning to any doctor considering such a project. There are many examples of worthwhile studies throughout the book.

The following seven chapters concentrate on individual topics in women's health. Each contains a summary of the subject, amusing case studies and suggestions for learning plans. The case studies are not directly related to gathering evidence and at times seem to break up the flow of the text. The topic summaries are at a very basic level of knowledge, for example: "checking blood pressure before giving contraceptives containing oestrogen is essential". It is unclear where this fits in with demonstrating competence. The information would be useful to medical and nursing students but I would expect doctors and specialist nurses to have this knowledge already.

Each chapter has a very useful reference section and suggested further reading, including websites. The chapter on the menopause is out of date with regard to hormone replacement therapy.

This book attempts to combine a textbook on women's health with a practical guide to collecting information for appraisal and revalidation. The reader is in danger of getting lost between the two. It is a useful reference book to help doctors with appraisal and to guide them through the steps involved to collect evidence. However, it is too superficial to be a useful textbook on women's health.

Reviewed by Dr Lesley Smart, MRCGP $G P$, Midlothian, $U K$ 